\title{
A wormy surprise: ERCP for intrabiliary drainage of a hydatid cyst
}

A 41-year-old man with a known hepatic hydatid cyst presented with several months of abdominal pain and more recent onset of jaundice. Despite repeated courses of albendazole, he reported no clinical improvement. Upon presentation, he underwent magnetic resonance cholangiopancreatography (MRCP), which revealed a multiloculated cystic structure within hepatic segments 5 and 6 , measuring approxi-

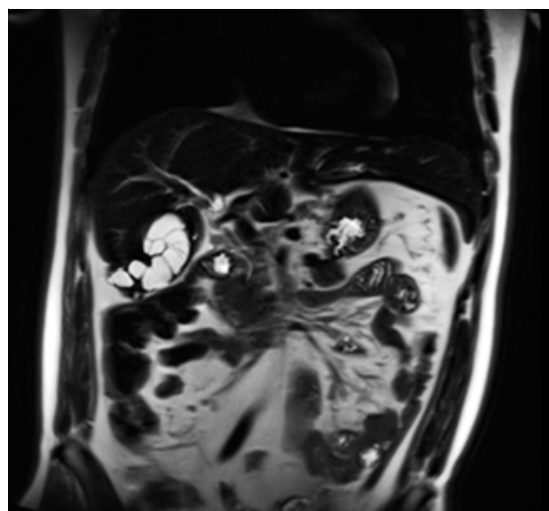

- Fig. 1 Magnetic resonance cholangiopancreatography image showing a multiloculated cystic structure within hepatic segments 5 and 6 , measuring approximately $7 \times 4.5 \times 6.5 \mathrm{~cm}$ with enhancing septations, and diffuse intrahepatic biliary ductal dilatation. mately $7 \times 4.5 \times 6.5 \mathrm{~cm}$ with mildly enhancing septations, and diffuse intrahepatic biliary ductal dilatation ( $\mathbf{F i g . 1}$ ). The patient underwent an endoscopic retrograde cholangiopancreatography (ERCP) with the initial cholangiogram showing a hilar filling defect, a common bile duct (CBD) stricture, and dilated intrahepatic ducts in segments 5 and 8 ( $\vee$ Fig. 2a). A biliary sphincterotomy was performed and the cholangioscope was advanced over the wire into the CBD, where cyst membranes were visualized

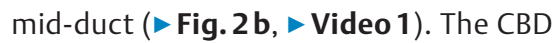
was then dilated with a balloon catheter and copious amounts of cyst membranes were swept from the duct ( $\nabla$ Fig. $\mathbf{2} \mathbf{c}$ ). The cyst membranes were collected with a Roth Net and sent to microbiology. After multiple balloon sweeps, the cholangioscope was re-inserted into the bile duct and complete clearance of cyst membranes was confirmed. A $10-\mathrm{Fr} \times 7-\mathrm{cm}$ straight plastic stent was deployed in the $\mathrm{CBD}$ at the end of the procedure.

The patient was treated with albendazole and returned a few days later for an extended right hepatectomy. His postoperative course was complicated by a bile leak that required repeat ERCP and placement of a long plastic stent to cover the defect causing the observed leak.
The patient was seen at follow-up and continues to remain free of both symptoms and cysts.

While surgical resection has been the mainstay in the approach to the management of hepatic hydatid cysts, ERCP can be a useful modality both to aid in the diagnosis of hepatic cyst extension into the bile ducts and for therapeutic drainage of the tapeworm cyst and membranes.

Endoscopy_UCTN_Code_TTT_1AO_2AZ

\section{Competing interests}

Reem Z. Sharaiha is a consultant for Boston Scientific and Apollo Endosurgery.

The authors

Shawn L. Shah, Ming-ming Xu, Enad Dawod, Karim Halazun, Reem Z. Sharaiha

Division of Gastroenterology and Hepatology, New York-Presbyterian/Weill Cornell Medical Center, New York, New York, USA
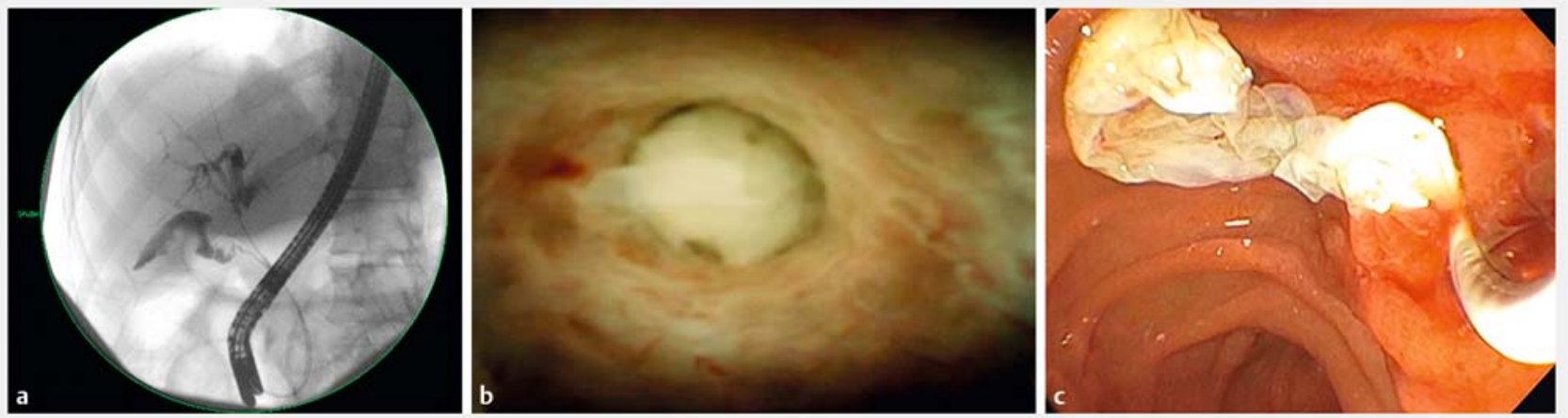

- Fig. 2 Images from the endoscopic procedure to remove cyst membranes from the common bile duct showing: a a hilar filling defect on the initial cholangiogram, along with a common bile duct stricture and dilated left and right intrahepatic ducts in segments 5 and 8; $\mathbf{b}$ cyst membranes in the mid-duct on cholangioscopy; $\mathbf{c}$ the cyst membranes being swept through the ampulla using a balloon catheter. 


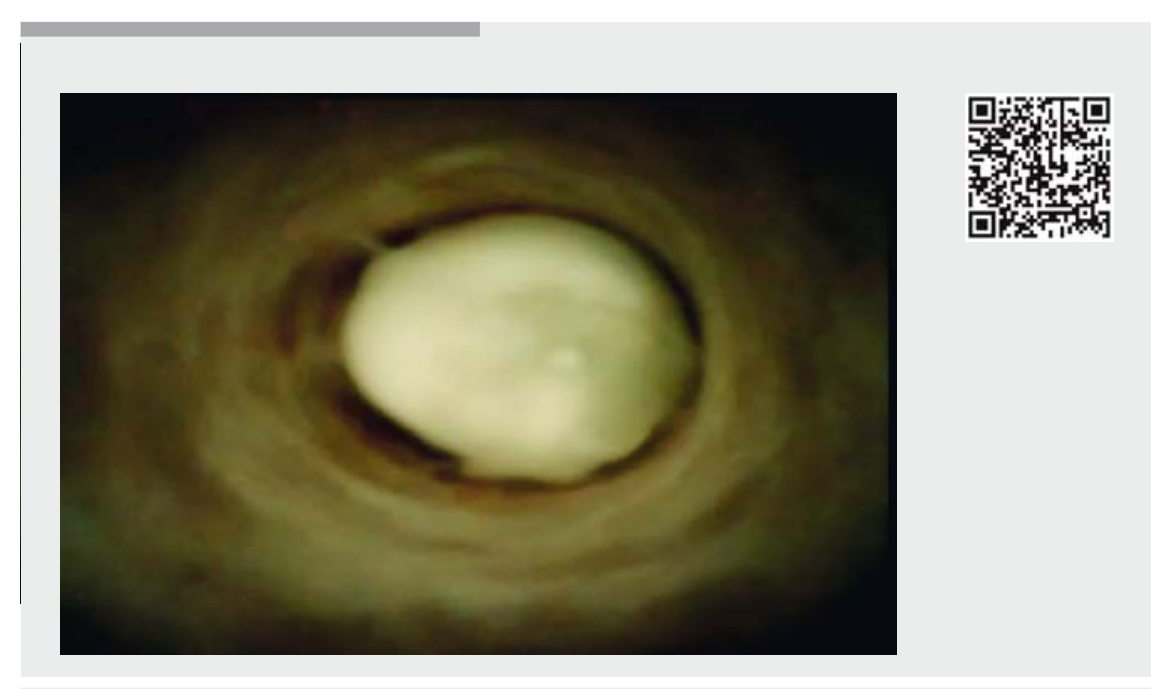

$\checkmark$ Video 1 Intrabiliary drainage of a hydatid cyst through cholangioscopy-guided endoscopic retrograde cholangiopancreatography.

\section{Corresponding author}

\section{Reem Z. Sharaiha, MD, MSc}

New York-Presbyterian/Weill Cornell

Medical, 1305 York Ave, 4th Floor, New York, NY, 10065, USA

rsharaiha@gmail.com

\section{Bibliography}

DOI https://doi.org/10.1055/s-0043-123346

Published online: 19.1.2018

Endoscopy 2018; 50: E81-E82

(c) Georg Thieme Verlag KG

Stuttgart · New York

ISSN 0013-726X

\section{ENDOSCOPY E-VIDEOS}

https://eref.thieme.de/e-videos

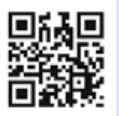

Endoscopy E-Videos is a free access online section, reporting on interesting cases and new

techniques in gastroenterological endoscopy. All papers include a high quality video and all contributions are freely accessible online.

This section has its own submission website at

https://mc.manuscriptcentral.com/e-videos 